\title{
Intensidades y retóricas del texto audiovisual
}

\author{
Gian Maria Tore \\ (Universidad de Luxemburgo)
}

Recibido: 17/1/2011

Aceptado: 4/2/2011

\begin{abstract}
Resumen: Las páginas que siguen se proponen desarrollar una concepción semiótica que se apoya esencialmente en las teorías de Louis Hjelmslev y de Claude Zilberberg. A través del estudio de un texto audiovisual, el incipit del filme Pickpocket de Robert Bresson (1959), no se tratará de ilustrar la semiótica de Hjelmslev ni de Zilberberg, y menos aún de aplicarla; se trata más bien de experimentarla, puesto que dicha teoría textual no ha sido aplicada o lo ha sido escasamente, al dominio de lo audiovisual. ${ }^{1}$ Nos atendremos, por una parte, a dar cuenta, con esa teoría, del texto fílmico en cuestión; y por otra parte, a mostrar su interés y su alcance heurístico, tanto para la teoría del lenguaje como para los estudios fílmicos.
\end{abstract}

Palabras clave: Semiótica del cine / análisis fílmico / retorica visual / texto fílmico

\section{Intensities and rhetoric of the audio-visual text}

Summary: The following pages aim to develop a semiotic conception that is essentially based on the theories of Louis Hjelmslev and Claude Zilberberg. Through the study of an audiovisual text, the incipit of the film of Robert Bresson's Pickpocket (1959), it won't attempt to illustrate the semiotics of Hjelmslev or Zilberberg, or implement it, since that textual theory has not been applied or has been poorly, the audiovisual domain, to experience it. We will comply, first, to give account of that theory, the text of the film in question, and secondly, to express their interest and scope heuristic, both for language theory to film studies.

Keywords: Semiotics of cinema / film analysis / visual rhetoric / film text

1 Por cierto que no hay que olvidar el ensayo sumamente importante de Christian Metz, Lenguaje y cine (1971). Pero no solo ese ensayo ha sido, lamentablemente, pronto olvidado (diríamos que hasta por Metz mismo); sobre todo porque su inspiración es el Hjelmslev de los Prolegómenos a una teoría del lenguaje, y no el Hjelmslev "morfemático" y "prosódico". Cf. la nota siguiente. 


\section{Un marco para una semiótica del texto audiovisual}

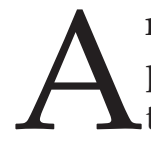

ntes de abordar nuestro corpus, vale la pena que nos detengamos un poco en la pareja de teóricos Hjelmslev-Zilberberg y en sus aportes a la semiótica, y luego, a su utilidad para el estudio del texto audiovisual. Con relación a la semiótica estructural, el rol de Zilberberg ha consistido en darle un lugar central al Hjelmslev "prosódico", según el cual, en todo texto, existe un orden de elementos y de funciones "componentes" $\mathrm{y}$ un orden de elementos y de funciones "constituyentes", y este último dominio, regulado por acentuaciones intensivas, y por modulaciones extensivas, ${ }^{2}$ o desregulado: un texto no está solamente compuesto, sino también, y ante todo, dotado de cierta "consistencia". Ahora bien, Zilberberg justamente ha insistido sobre la variabilidad de dicha consistencia: sobre la variación del "tenor" de los componentes y sobre los retos semióticos que de eso se derivan; sobre la importancia capital de los hechos "tensivos" y sobre la "retórica" que los ordena. ${ }^{3}$

Semejante concepción tensiva y retórica de la semiótica toma la dirección contraria de dos aproximaciones académicas entre las más sólidas, en el campo de los estudios fílmicos, como también en el de las ciencias humanas. Una es la aproximación cognitivista, que en los estudios fílmicos se conoce como neoformalista: también ella propone un estudio de la retórica audiovisual, pero, extrañamente, esa retórica está vacía de todo efecto semiótico. Así, un análisis neoformalista particularmente rico de Pickpocket ${ }^{4}$ llega a concluir

2 Recordemos, aunque sea de manera rápida, que Hjelmslev distingue entre "constituyentes" (o "exponentes") y "componentes". Los primeros, en el plano de la expresión, se denominan "prosodemas"; en el plano del contenido, "morfemas". Tanto los unos como los otros constituyen eso que da a toda cadena textual la "consistencia" de su "composición", puesto que la orientan en una "(di)rección", ya concentrada ("intensidad"), ya desplegada ("extensidad") -ver dos ensayos esenciales: "Essai d'une théorie des morphèmes" y "The syllabe as structural unit"; así como, en un plano más general, La categoría de los casos y El lenguaje (las referencias se encuentran al final de este artículo).

3 Véase la última presentación sistemática de Cl. Zilberberg, "Le double conditionnement -tensif et rhétorique- des structures élémentaires de la signification" (Alonso 2006). Una puntualización significativa sobre la "semiótica tensiva" de Hjelmslev en la generalización zilberbergiana se encuentra en Zilberberg 2002. Acerca de la concepción tensiva de la retórica, véase Fontanille y Zilberberg 1998, especialmente el capítulo "Praxis", así como en Fontanille 2003, y en Zilberberg 2006, “Semiótica y retórica”, cap. V de la primera parte de Semiótica tensiva.

4 Narration in the Fiction Film (Bordwell 1985: 289-310). Este libro ha marcado el nacimiento de la ola cognitivista en los films studies anglosajones. 
que en ese filme "los efectos" [de sentido] surgen de una manipulación formal que es, en sentido fuerte, insignificante (nonsignifying) (Bordwell 1985: 306, subrayado en el texto): el filme consistiría en la imposición de un estilo sin significación ni finalidad en sí mismo. ${ }^{5}$ Pues bien, en nuestro corto análisis queremos demostrar exactamente lo contrario, es decir, que la retórica del texto (su "estilística", si se quiere) es precisamente la que gerencia el sentido de los componentes del texto mismo: ella produce, regula o desregula el tenor de las diferentes figuraciones; ella orienta su valor. Dicho de otro modo: difícilmente se puede explicar el sentido de lo que se ve y se oye dejando de lado las operaciones "constituyentes" del texto, las intensificaciones y las modulaciones de las figuraciones, en breve, su retórica audiovisual.

La otra aproximación que suele adoptarse en el análisis fílmico y cuestionada por el textualismo hjelmsle- viano y zilberbergiano es la narratología y sus derivados. A diferencia del acercamiento cognitivista, la aproximación de tipo narratológico está, ciertamente, atenta a la construcción del sentido en el texto; sin embargo, también ella vira a una concepción representacional del texto: lo mismo que en el acercamiento neoformalista de los cognitivistas, para la narratología cada texto narrativo es, en el fondo, un modo de representación particular de ciertos acontecimientos. Pues bien, nosotros quisiéramos mostrar que en un filme como Pickpocket el sentido de los acontecimientos no es tanto el producto de una representación sino que surge de una red de transformaciones. Dicho de otro modo, el acontecimiento atestiguado en nuestra secuencia (el robo de un carterista) es menos un asunto de identificación de actores, de acciones y de lugares, que de una diferenciación de la figuración entre órdenes de valores en tensión entre ellos. De tal modo que lejos de ser un "todo de significación",

5 En efecto, según el cine-cognitivismo, la significación de un filme no reside más que en la identificación de la "intriga", entre de una parte, operaciones semánticas universales, cuyo producto sería una "fábula", y de otra parte, operaciones más particularmente fílmicas, cuyo producto sería un "estilo" (véase especialmente Bordwell 1985, capítulos 4 y 12). En suma, para Bordwell y los cognitivistas del cine, la retórica audiovisual (cuyo efecto final y coherente es el "estilo") solo sirve para poner de relieve o dejar en la sombra la "intriga". Eso sería ejemplar en Pickpocket, intriga "subordinada a una estructuración estilística inmanente" (Bordwell 1985: 305) y oscurecida por la emergencia de un "[...] estilo potente y muy sólido [que] rehúsa los esquemas convencionales de la producción de la significación" y que resiste obstinadamente "[...] a la interpretación, [con] su preferencia por el orden antes que por la significación" (Bordwell 1985: 306).

6 Según la expresión y la concepción semiótica de Jacques Geninasca (1997, passim). 
la secuencia hace sentido por una heterogeneización irreductible de los componentes, algunos de los cuales revelarán que son sólidos, estables; otros, que son deshilvanados, precarios. Cuestión de consistencias diferentes.

\section{La retórica visual de Pickpocket (primera parte): Figurar y valorizar}

Pasemos al análisis de la secuencia inicial de Pickpocket. Según la concepción narratológica, deberíamos poder explicar su sentido por medio de una "macro-proposición"7 del tipo "[...] un joven carterista comete un robo en perjuicio de una dama elegante en el hipódromo de Longchamp, durante una carrera de caballos", añadiendo que el discurso es filtrado por el mundo cognitivo del protagonista, que relata la escena en flash-back. ${ }^{8}$ Pero desde una primera aproximación del texto, podemos percibir fácilmente que tal explicación semiótica es marginal, si no errónea.

Abordemos la cuestión desde el punto de vista del protagonista: como acabamos de indicar, la narratología o las aproximaciones semióticas similares subrayarían que la secuencia respondería al relato hecho por el protagonista, que cuenta con su voz en off. Puede ser. Pero, primero, queda claro que eso no explica nada que no se entienda inmediatamente a la visión del filme; lo único que añade es una etiqueta tipológica, es decir, asigna el filme a una de las clases posibles de narración. En segundo lugar, tal posición deja de lado el proceso de producción de la figuración de la secuencia, y por tanto sus efectos: dando una identidad a la figuración audiovisual, desconoce precisamente el no-saber que la acompaña, entre otras cosas a causa de la voz misma. En efecto, en esa secuencia -y no en la síntesis trascendental, no en la representación que de ella se puede dar- nada indica que la voz oída es la voz de la protagonista: nada ha podido mostrarlo antes puesto que estamos al inicio mismo del filme y el protagonista ni siquiera ha abierto la boca. Simplemente, el texto audiovisual, tal como está dispuesto, deja oír a alguien que habla en primera persona,

7 El análisis por "macro-proposiciones" fue avanzado por la semiótica textual de Umberto Eco (1985), según el cual -lo mismo que para Bordwell- la "lectura" de un texto es el conjunto de las operaciones cognitivas que permiten la identificación de la intriga discursiva y su paso a la fábula por la formulación de un conjunto de macroproposiciones lógiconarrativas, si bien para Eco a diferencia de Bordwell, eso desemboca en la experiencia de amoblamiento de los mundos posibles.

8 Más precisamente, habría que decir que en la aproximación narratológica se trata de una voz "intradiegética" (es decir, personificada) "homodiegética autodiegética" (es decir, que forma parte de la historia y en primera persona) (véase especialmente Genette 1972, capítulos 4-5). 
$\mathrm{y}$ hace ver al mismo tiempo a alguien que actúa... Ciertamente, la secuencia va precedida de un plano muy importante donde se ve la mano del protagonista escribiendo el diario íntimo y se escucha su voz que lee lo que escribe: ese plano instaura un relato autobiográfico y sobre todo autográfico, el cual se extenderá también a nuestra escena del robo. Pero no es menos cierto que esas identificaciones se dejan creer, pero no son atestiguadas: son potenciales y no actualizadas. En la secuencia en cuestión nada indica que:

- la voz en off escuchada sobre el diario íntimo y luego sobre la secuencia del robo sea la misma del personaje que comete el robo (porque ahí este último no abre la boca);

- la voz en off pertenezca a la mano que escribe el diario (¿por qué no pensar, por ejemplo, que la voz está dictando sus confesiones a un policía?);

- esa mano que escribe el diario sea la misma mano que comete el robo en el hipódromo.

En suma, la debilidad de una aproximación que pretende representarse los acontecimientos consiste en que termina por saber más que el texto mismo: ve lo que no se muestra. ${ }^{9}$ En nuestro caso, su problema gravísimo consiste en proponer la existencia de un mismo actor, de un mismo orden de acciones, a partir de un punto de vista determinado, que enunciase un relato cohesivo. ¿Qué pasa entonces con las diferenciaciones figurales que, por el contrario, constituyen el texto?

La aproximación narrativa greimasiana -de la cual la teoría de Zilberberg es a la vez un cuestionamiento y un desarrollo- nos ofrece ya una concepción más fina del proceso de producción de los valores textuales. De hecho, aunque ese acercamiento es "discursivo" y no "textual", puede articular el texto según sus diferenciaciones; explicarlo por los avatares del objeto de valor que contiene. En un texto tan simple como nuestra secuencia del robo, eso puede comprobarse con cierta capacidad analítica: se puede explicar el robo como un acontecimiento constituido por tres frases de una misma transformación:

I. entrada al hipódromo: disposición de los actantes $\Longrightarrow$ virtualización del objeto de valor;

II. robo junto a la pista, durante la carrera: confrontación interactancial $\Longrightarrow$ actualización del valor;

III. salida por lugares parcialmente similares a los de la entrada: conjunción con el objeto de valor y eventual sanción $\Longrightarrow$ realización.

Si eso es así, tal tripartición sigue proponiendo una semiótica elemental,

9 Sobre la debilidad epistemológica de toda aproximación poskantiana, iconográfica, representacional, véase Didi-Hubermann 1990. 
lineal, unitaria: tenemos que preguntarnos si nuestro texto presenta realmente una figuración con un desarrollo tan cohesivo, una sintaxis tan coherente.

Examinemos con más detalle las figuraciones audiovisuales de la secuencia. La tarea resulta fácil por el hecho de que la figuración visual y la figuración sonora son producidas de manera distinta: por el momento, examinaremos solamente la figuración visual; después, consideraremos los efectos de su interacción con la figuración sonora.

Visualmente, el filme se desarrolla con cierta economía figurativa. A falta de poder disponer de las imágenes en movimiento del filme, es imprescindible hacer una breve descripción, según la tripartición en sintagmas, que mantenemos:

I. Entrada al hipódromo / virtualización del objeto de valor (dinero a robar): planos 1 a 3 .

En el plano 1, vemos a una dama sacar dinero de su cartera y entregárselo a un hombre que lo entrega a su vez a un cajero, ante el cual otras personas hacen lo mismo. En el plano 2, vemos siempre un grupo de personas, y la figura destacada de un hombre que contempla la escena que acabamos de describir (se trata de un contracampo). En el plano 3, la muchedumbre y los tres actores precedentemente distinguidos caminan, juntos, bajo una arcada (plano de síntesis clausurante).
Ese sintagma es formalmente recogido por el sintagma III, que le es especular:

III. Salida de los mismos lugares / realización del carterista (con el dinero robado): planos 13 a 15 .

Aquí también hay tres planos; en el primero como en el segundo de esos planos (13 y 14), encontramos la misma figuración del plano de clausura del sintagma I (plano 3): nuestros tres actores, la dama, su acompañante y el ladrón, quienes, entre la muchedumbre, pasan bajo una arcada. Solo en el tercer plano 15) se produce una ligera variación con el sintagma I: el protagonista sale del hipódromo franqueando las rejas de entrada; y allí donde en el sintagma I miraba a las dos personas para atracarlas, aquí es él el que es individualizado y abordado por otras dos personas (que son dos policías). Se da, pues, una inversión figurativo-narrativa, que se desarrollará en los planos sucesivos, y que no tomaremos ahora en cuenta.

Los dos sintagmas, I y III, enmarcan un núcleo central:

II. Espectáculos de la carrera de caballos y del robo del dinero / transformación: planos 4 al 12.

El sintagma central (II) merece una descripción más atenta de las particularidades textuales de la figuración, es decir, de los modos como el discurso es conducido por la enunciación fílmica. El primero 
de los planos del sintagma (plano 4) prolonga el plano precedente (plano 3): muestra la continuación del paso bajo el arco. Consiste en un travelín adelante, que comienza con un plano americano (forma textual exclusiva del sintagma) y termina con un primer plano del rostro (hápax legomenon * de la secuencia entera). De ese modo, por el travelín adelante, la "prolongación" es literal; por otra parte, produce una transformación intensiva de la figuración: el travelín, que avanza hasta un primer plano, muestra que la figuración es una prolongación llevada hasta la basculación en la novedad.

Es esencial recordar que, desde el inicio, el sintagma central consiste en una repetición-transformación intensiva. En efecto, los planos siguientes operan de la misma manera, pero la repetición-transformación intensiva se radicaliza en ellos: se trata de un mismo par de planos (5-6) que se repite cuatro veces (planos 7-8, 9-10, 11-12). El primero de los planos de cada par (planos 5, 7, 9 , 11) reúne, de una manera frontal y cercana, a los tres personajes del sintagma I; el segundo (planos 6, 8, $10,12)$ muestra el detalle de basculación de las relaciones entre las figuras: una mano roba el dinero del bolso de la dama. Esa repetición- transformación-repetición transformada o transformación repetida produce un doble efecto. Por el lado textual, estabiliza la tendencia anunciada por el primer plano del sintagma, el plano en trávelin adelante con zoom: la tendencia a pasar a una figuración cercana e incluso muy cercana. Por el lado figural, produce una concentración de valor en la mano en trance de robar, con un clímax que culmina en el plano final cuando el dinero es extraído del bolso. La inversión es entonces completa, la transformación cumplida: el dinero que la mano elegante colocaba en el bolso al comienzo de la secuencia, sale ahora en la mano del ratero.

Esta primera descripción analítica de la secuencia hace aparecer claramente que el conjunto de las operaciones de textualización (la "estilística") fílmica, lejos de ser insignificante, afecta directamente el valor del discurso fílmico: porque dispone en el texto fílmico los componentes figurativos según consistencias diferentes. Más precisamente, vemos que la figuración es textualizada de acuerdo con tres operaciones retóricas: la reiteración, la sinécdoque y la elipsis; combinadas todas ellas con una argumentación concesiva.

Así, en el sintagma central (II), el hecho esencial de la textualización

Con esta expresión se designa todo rasgo lingüístico que se documenta una sola vez. Abreviado: hápax. [N. del T.] 
fílmica consiste en que no se ve la carrera de caballos, acontecimiento no obstante esencial para saber que nos encontramos en un hipódromo, como lo ilustramos más adelante, la carrera de caballos, y el hipódromo en general, no son configurados de una manera estable y definitiva más que gracias al sonido. Se trata, pues, de una elipsis visual, la cual, con toda evidencia, obedece a una argumentación concesiva: no se muestra aquello que de antemano es asumido como necesario (justamente la carrera y su espectáculo), y se le da mayor valor a algo que de antemano se considera sin ninguna importancia (el robo de un ratero). ${ }^{10} \mathrm{De}$ tal modo que el robo se produce más bien como un accidente en el hipódromo: algo que no contaba con suceder allí por derecho, ocurre de hecho y tiene, en el filme, la mayor importancia. El robo, convertido en una transformación intensiva central en el texto fílmico, se realiza como algo que sobreviene [que ocurre de improviso, súbitamente] en el hipódromo, dado como marco de fondo: en eso consiste la aventura semiótica. ${ }^{11}$

Al lado de la elipsis, la reiteración y la sinécdoque producen también ese accidente, realizan esa aventura. La reiteración iniciada por el par de planos (5-6) entorpece el desarrollo de los acontecimientos; la sinécdoque del conjunto [mano-cartera-dinero] permite ver un accidente por medio del cual un joven se convierte en una mano, la dama se reduce a la cartera, la interacción intersubjetiva se resume en una circulación de dinero. De ese modo, elipsis, reiteración y sinécdoque, combinadas de manera concesiva, forman un conjunto de operaciones retóricas que textualizan la figuración de una manera accidental. Lo cual quiere decir que el sentido del texto parece ser el de romper la homogeneidad cohesiva y coherente de una figuración determinada y estable, como la de la carrera de caballos en el hipódromo, con sus protagonistas y con un carterista infiltrado. El sentido de nuestra secuencia consiste en producir desvíos visibles, en figurar diferencias.

Nos queda por precisar cuáles son los componentes diferenciados, es decir, las figuraciones de consistencia variada y en tensión recíproca: y sobre todo, explicar la significación engendrada con esa tensión. Sigamos con la figuración visual, cuya semiosis concesiva acabamos de indicar; luego pasaremos a analizar el complejo audiovisual. Hasta el plano 5, el espacio fílmico del hipódromo se define por

10 Zilberberg ha hecho de la concesión la operación esencial de producción discursiva del evento, por oposición a la implicación, en la cual los valores dados de antemano son desarrollados y no contrariados. Véase especialmente "Elogio de la concesión" (2004).

11 Según la fórmula conocida de Roland Barthes (2002), fórmula que corresponde perfectamente a la concepción zilberbergiana de la semiosis como evento, como sobrevenir imprevisto. 
una serie de raccords, basados en movimientos del encuadre y de las miradas. No vamos a analizarlos aquí, pero resulta claro que los raccords producen en el texto fílmico una figuración cohesiva (un "todo de significación"). A partir del plano 6, y luego por cuatro veces, esa lógica del raccord es quebrantada: y así, la unidad de lugar y de acción, que se conoce como "escena",12 es llevada a sus límites. Asimismo, el efecto del "estilo" concesivo del texto aparece con toda claridad: producir un espacio discursivo no continuo y unitario (una "escena"), sino un espacio difractado.

En una primera "concesión", el espectáculo de la carrera de caballos se presenta solamente a través de los rostros poco expresivos de los espectadores, es el primer plano del par (5-6). En una "concesión" ulterior, el espectáculo de la carrera es denegado de manera decisiva a favor de otro espectáculo, de naturaleza y de valor totalmente diferentes: el robo, en el segundo plano del par. El hecho de que esa disposición binaria sea repetida cuatro veces no hace más que enfatizar tal desvío, reforzando así la heterogeneización de la figuración. Cada vez más, en el curso de su reiteración, los dos planos parece que funcionan, respectivamente, como un plano de $a b$ sorción y un plano de ruptura. En efecto, cada vez, en el primero de los planos del par, parece que no pasa nada, salvo que los tres actores de la escena están reunidos en cuanto espectadores de la carrera de caballos; esa es toda la concesión que se hace al hipódromo, enteramente absorbido por ese hecho fílmico insignificante, y por lo mismo desvalorizado. Porque no solamente no se deja ver en él la carrera, quedando elíptica su figuración, sino que, además, la figuración actualizada es parcial, imperfecta, mal realizada: los espectadores con miradas amorfas están mal encuadrados (la dama y su acompañante están cortados en dos). Y, a pesar de su insignificancia, esa figuración es repetida cuatro veces sin que ningún cambio intervenga; por otra parte, es prolongada hasta alcanzar duraciones extraordinariamente largas: respectivamente, 28, 10, 16 y 8 segundos. El efecto consiste en crear una suerte de tabula rasa para la emergencia del "evento" en el plano que sigue, el plano de ruptura, el plano muy cercano de la mano en el bolso de la dama. En ese segundo tipo de plano, la figuración no es reiterada de la misma manera monótona como se hace en el plano de absorción, sino de acuerdo con un climax de intensidad ascendente: cada vez, una nueva frontera es franqueada: primero, la mano se acerca al bolso, después, lo abre, luego, la mano

12 Para nuestro análisis es importante recordar que -en la praxis textualizante del cine, como en la praxis teatral y novelesca- la "escena" es la textualización de una figuración espacial, temporal y actorial unitaria. 
entra en el bolso, y finalmente sale con el dinero. Se genera ahí una verdadera progresión cualitativa, la cual es intensificada por la retórica de la alternancia contrastiva con los planos del espectáculo vaciado de sentido del hipódromo. En contraste con estos dos últimos, en los planos del robo se produce un estrechamiento de la extensión figurativa (del plano general, que abunda de espectadores mal encuadrados, al plano de detalle de la mano sobre el bolso), que es también reducción de la duración (incomparablemente más corta: 6 segundos contra 28, 5 contra 10, 3 contra 16, 3 contra 8).

En conclusión, de este análisis de la sola figuración visual de la secuencia, vemos en qué sentido las operaciones de textualización, lejos de ser la emergencia de un estilo "insignificante" como pretende el análisis cognitivista neoformalista, es una verdadera producción de valor de lo visible. $Y$ vemos también cómo esa producción del valor de los componentes visuales (los planos con los actores y los espacios que contienen) está regulada de manera prosódica: el sintagma del robo actualiza claramente el desafío semiótico de desplazar el acento intensivo del espacio social del hipódromo al espacio individual de la acción del carterista, después que los dos espacios han sido heterogeneizados.
Contra una concepción semiótica estandarizada, que la semiótica «retórica» nos ayuda a superar, resulta claro que el discurso, y hasta el relato, consiste aquí no en una homogeneización, ni en una unificación, sino en una alteración, en un desvío de la espacialidad discursiva. El sentido de la secuencia consiste precisamente en crear una espacialidad nueva con relación a la espacialidad asignada a los sintagmas I y III, y a los dos primeros planos del sintagma II. La espacialidad "asignada" a esos sintagmas y planos es colectiva, intersubjetiva, $y$ consiste en pasajes entre extensiones equivalentes: las ventanillas, los arcos, las rejas de entrada y de salida, y también la pista de carreras, así como los tres actores que son encuadrados de cualquier manera, con una temporalidad fútil, sin consistencia, en una escena átona. La espacialidad que, por el contrario, hace sentido por no estar dada de antemano, es decir, por ser accidental e inesperada [producto de un "evento"], y por tanto difícil, consiste no en pasajes, sino en saltos cualitativos: la mano que se aproxima al bolso, lo abre, se introduce en él y saca el dinero. Así, la espacialidad "dada" de umbrales reversibles es desviada, heterogeneizada a una espacialidad "no dada" de límites decisivos. ${ }^{13}$

13 Sobre las retóricas de "umbrales" y "límites" como estrategias opuestas de valorización, véase Zilberberg 2002. Acerca de una semiótica más general que acoge las cuestiones de las modelizaciones del espacio a partir de los conceptos de "inicio" y de "fin", cf. Lotman y Uspenskij 1975: 135-248. 
Para resumir este primer momento del análisis, diremos que el sentido de la secuencia consiste en actualizar una figuración y en escindirla:

- por un lado, para hacerla significar como una figuración "cualquiera" (porque el hecho de que aparezcan un hipódromo, una dama y un señor deja rápidamente de tener importancia: se convierte enseguida en algo "dado");

- por otro lado, para incrustar allí un valor "singular" y para darle una significación a la vez local y absoluta (puesto que es propia de cierto momento, de un plano determinado del filme, y al mismo tiempo, libre de toda determinación circulante, desconectada de toda coordinación más general). ${ }^{14}$

\section{La retórica audiovisual de Pickpocket (segunda parte): Heterogeneizar lo semiótico}

Pasemos ahora a un análisis de la figuración sonora. Veremos enseguida la legitimidad de un análisis separado de la imagen y de los sonidos: mostraremos que el sonido produce una tercera espacialidad, diferente de las dos que acabamos de estudiar.
El conjunto de la figuración sonora de nuestra secuencia se compone de dos procesos bien distintos: los llamados ruidos de ambiente y la voz en off. Comencemos por los primeros, y notemos que el hipódromo representado por ellos se parece solo parcialmente al representado por las imágenes; no se parece en absoluto al espacio del robo. El hipódromo "escuchado" contiene una espacialidad que no es ni una espacialidad de umbrales, ni una espacialidad de límites. Constituye más bien una espacialidad de lo continuo. Nada de pasajes ni de saltos, de escansiones ni desvíos; por el contrario, un conjunto extremadamente cohesivo donde las figuras se mezclan. Además, esa espacialidad es homogénea y coherente: la figuración sonora del hipódromo no está segmentada y seleccionada (nada de elipsis ni de sinécdoques); contiene la totalidad de las actividades colectivas de ese espacio; actualiza todo lo que se espera de ese espacio. El hipódromo escuchado a través de los sonidos de ambiente es, de hecho, el objeto discursivo en el que se encuentran anuncios en los altoparlantes, ventanillas de apuestas, grandes gritos, el desarrollo de las carreras (escuchado por los parlantes), pasos que van y vienen... En suma,

14 Sobre la imagen/figuración "cualquiera" y la significación que produce en los filmes véase Mitry 2001: 53 ss., donde también se propone una teorización general del lenguaje cinematográfico. Acerca del cine de Bresson en particular y sobre el espacio "cualquiera" como base para la producción de una ruptura cualitativa, véase Deleuze 1983, capítulo 7. 
ahí se juntan el paso de las gentes y la circulación del dinero con las carreras completas de caballos: lo que quiere decir que ahí nada se presenta en forma "concesiva", nada sobreviene fuera de lo esperado, puesto que la figuración es total; y por lo tanto, nada surgirá ahí por "accidente"; es decir, de manera imprevista y súbita.

En los hechos, solamente en el sonido se puede producir por completo la figuración unitaria, "escénica", del hipódromo de Pickpocket; solamente allí la figuración es isótopa, cohesiva y coherente. Por consiguiente, atribuir esos mismos caracteres a la configuración audiovisual entera sería ignorar que, en el filme, están en juego otros modelos figurales, $y$, en especial, otras espacialidades. La tabla que sigue a continuación resume esas diferencias, haciendo del pretendido "todo de significación" de nuestra secuencia una espacialidad triple: una objetividad incierta en tensión entre tres figuraciones:

No nos detendremos en dar una explicación metasemiótica de la tabla. Indicaremos solamente que el "objeto" es aquí la figuración particular de un espacio; el "modelo", la regulación topológica de base, que hubieran podido o podrían tener otros objetos particulares en otros textos. Lo que importa

\begin{tabular}{|c|c|c|c|c|}
\hline \multirow{3}{*}{ 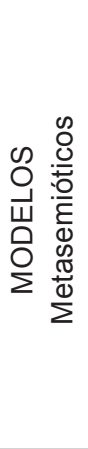 } & $\begin{array}{l}0 \\
0 \\
\frac{0}{0} \\
\frac{\pi}{0} \\
\frac{0}{\overline{0}} \\
\frac{\pi}{0} \\
\frac{\pi}{0} \\
\frac{0}{0} \\
w\end{array}$ & $\begin{array}{l}\text { Totalidad } \\
\text { unitaria }\end{array}$ & $\begin{array}{c}\text { Umbrales } \\
\text { de la totalidad } \\
\text { unitaria }\end{array}$ & $\begin{array}{c}\text { Límites } \\
\text { desmultiplicadores }\end{array}$ \\
\hline & 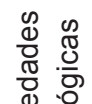 & $\begin{array}{c}\text { cohesión } \\
\text { (espacio fusionado) }\end{array}$ & $\begin{array}{c}\text { cohesión } \\
\text { (espacio en raccords) }\end{array}$ & $\begin{array}{c}\text { ni cohesión } \\
\text { (espacio a saltos) }\end{array}$ \\
\hline & 을 응 & $\begin{array}{l}\text { y coherencia } \\
\text { (global) }\end{array}$ & $\begin{array}{c}\text { sin coherencia } \\
\text { (elíptica y reiterada) }\end{array}$ & $\begin{array}{c}\text { ni coherencia } \\
\text { (sinécdoque y reiteración) }\end{array}$ \\
\hline \multirow{2}{*}{ 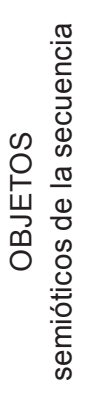 } & 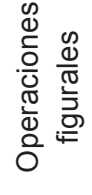 & $\begin{array}{l}\text { (puesta en) } \\
\text { escena }\end{array}$ & Concesión & $\begin{array}{l}\text { (producción del) } \\
\text { accidente }\end{array}$ \\
\hline & $\begin{array}{l}0 \\
\stackrel{0}{0} \\
\frac{0}{0} \\
\frac{0}{0} \\
\frac{\pi}{5} \\
\frac{0}{4}\end{array}$ & Hipódromo & $\begin{array}{l}\text { Caso singular } \\
\text { de hipódromo }\end{array}$ & $\begin{array}{l}\text { Serie de gestos } \\
\text { hasta el robo }\end{array}$ \\
\hline
\end{tabular}


señalar aquí es hasta qué punto esa regulación de base otorga a la experiencia fílmica toda su consistencia. Lo cual quiere decir que el sentido no reside solamente en el conjunto de sus figuraciones: el sentido de nuestra secuencia no depende de la identificación de un hipódromo y de un robo. El sentido surge de la articulación y de la valorización de lo audiovisual por una serie de operaciones retóricas de base, que aquí producen un hipódromo como una totalidad, primero, declinada de una manera singular después, y difractada finalmente en una serie de gestos completamente accidentales e imprevistos. Vemos, pues, por qué la figuración de Pickpocket está lejos de hacer sentido por medio de la intriga que uno puede identificar, de los personajes o de los lugares que podemos reconocer: hace sentido por los procesos de heterogeneización singular donde se producen.

La singularidad de la figuración de Pickpocket, explicable por la competición compleja que se produce entre diferentes procesos, queda sellada y corroborada por el último componente textual que vamos a analizar: la "voz en off". En nuestra secuencia, la voz en off se puede definir, primero, de manera negativa: es el elemento de la figuración sonora que no contribuye directamente a la realización de la escena audiovisual del hipódromo, ni a sus acontecimientos (sin los planos y sin los sintagmas analizados, sin los ruidos, no habría escena ni acontecimientos; pero sin la voz en off, sí). Esa es la trampa en la que caería aquí la aproximación narratológica, como lo advertíamos al comienzo: la voz de nuestra secuencia por más que sea sucesiva a los acontecimientos y pertenezca al que ha sido el protagonista de ellos, no explica en nada el contenido de la acción vista, ni influye en ella; no trata tampoco de ocultarla. De tal modo que hacia el final de la secuencia, en el sintagma III, parece incluso que existe una contradicción entre lo que la voz en off dice: "no tenía ya los pies en la tierra, yo dominaba el mundo" y lo que las imágenes figurativizan: dos hombres que abordan al protagonista. Solamente después de ese contraste, la voz puntualiza, con retraso: "pero un minuto después, estaba preso". Vemos, pues, que incluso si de antemano tuviéramos aquí condiciones para una focalización interna (anuncio de un relato, al comienzo; intervención en tiempo imperfecto...), eso no significaría nada: son los efectos prosódicos, tensivos y retóricos, los que cuentan. En el caso del final de la secuencia, donde el protagonista es capturado, lo que cuenta es el efecto de precipitación (tempo) de los acontecimientos (porque la voz va con retraso en relación con ellos), además de su pasionalización eufórica (intensidad): "no tenía ya los pies en la tierra, yo dominaba el mundo".

Más generalmente, en las intervenciones "en off", durante la secuencia entera, la importancia de la voz se mide por la manera como afecta a la figuración a lo largo de su extensión, 
en qué momento interviene para escandirla, qué tempo le imprime. ${ }^{15}$ En la secuencia que analizamos, como en el resto del filme, jamás la "voz" expresa un saber omnisciente; en todas partes en las que aparece, produce tensiones en la escena audiovisual: afecta siempre su "tenor": aquí, por medio de retrasos contrastantes; allá por medio de anticipaciones potencializadoras. Se trata siempre de cuestionar saberes y afectos más o menos "aceptados", más o menos "declinados".

Tengamos en cuenta ahora las otras dos intervenciones de la voz -la voz interviene tres veces en la secuencia: respectivamente, en los sintagmas I, II y III-. La primera intervención tiene lugar casi al principio de la escena, en el sintagma I. Cuando se ve circular el dinero de las apuestas y el joven protagonista anda por allí, se escucha: "desde hacía varios días, mi resolución estaba tomada, pero itendría la audacia?". Es evidente que tampoco aquí la voz se refiere a ningún contenido actual de las imágenes, y en nada las afecta; afecta más bien al tempo del sintag$\mathrm{ma}$, a la consistencia de la figuración. En efecto, hace que la figuración que vemos se encuentre en un estado de retraso posible: puede pasar cualquier cosa, aunque no es seguro. Produce el efecto de un ligero suspenso. Se revela entonces que el funcionamiento audiovisual del sintagma I es igual y contrario al del sintagma III, donde la voz pone la figuración en un estado de precipitación (sintagma III); algo distinto de una suspensión (sintagma I). Al intervenir en un momento o en otro de la acción figurada, la voz aporta una complicación modal: allí donde la acción hubiera podido resolverse simplemente, introduce un potencial, patemiza (la "decisión", la "audacia", la "alegría" que "eleva los pies de la tierra"...). El potencial está contenido en un enunciado, ciertamente, pero no se expresa sin afectar el proceso enunciativo del filme.

Consideremos la tercera intervención de la voz, que se sitúa en el sintagma II. Vemos al carterista aproximarse a la dama e intentar el golpe, mientras se escucha: "hubiera sido mejor que me fuera". La complicación modal de la acción, una vez más, es muy clara. En términos narrativos clásicos, se trata de una suspensión de la actualización del sujeto, es decir, de su estado de conjunción con el objeto de valor. Añadiremos que lo que se consigue es una modulación amplificante de la figuración, porque los tres espectadores de las carreras se encuentran

15 La importancia del tempo para la regulación de la eficacia del texto, y por tanto de su proceso semiótico, ha sido constantemente defendida por Zilberberg. Para una presentación de su teoría, véase Zilberberg 1995; cf. también "Centralidad del evento", capítulo IV de la primera parte, en Semiótica tensiva (2006). 
como "fuera de lugar": fuera del lugar de la voz, la cual valoriza alguna "otra parte" que es "mejor" que el "aquí".

En general, se puede apreciar que, con la voz, la figuración de la secuencia se encuentra escandida y modulada. Por una parte, las intervenciones de la voz escanden los momentos intensivos: lo mismo que un acento reparte la energía fonadora en una vocal y luego, en las palabras, las intervenciones de la voz marcan las etapas donde está en juego el valor de la secuencia; expresan los momentos fuertes de la figuración y de la pasionalización. En efecto, la primera vez, la voz interviene en el momento de la aparición del dinero, junto a la ventanilla de las apuestas; ahí marca la circulación del objeto de valor, su virtualidad. La segunda vez, lo hace en la aproximación a la dama con su bolso: la voz escande entonces la confrontación, la actualidad; la tercera vez, acentúa el robo mismo del ratero: la voz signa la posesión, la realización. En pocas palabras, la voz escande los tres sintagmas del texto fílmico: los acentúa en la medida en que constituyen las etapas problemáticas del recorrido del valor. Por otra parte, además de escandir los momentos intensivos por acentuación, la voz regula también la extensión de esos mismos momentos por medio de la modulación. Así como las entonaciones modulan los enunciados verbales, la voz administra el proceso fílmico en el sentido de una espera (o expectativa) cuando retrasa o suspende la acción (en su primera intervención), o en el sentido de una sorpresa cuando precipita la acción y es la voz la que va con retraso (en las otras dos intervenciones).

En síntesis, sea por medio de funciones de acentuación o por medio de modulaciones, queda claro que la voz no participa en la figuración de la escena del hipódromo, ni en la figuración del robo, puesto que no ofrece ninguna "información" pertinente relativa a esos acontecimientos. Su función consiste más bien en hacer porosa la división entre las dos escenas, en regular su dinámica. Si la voz estuviera ausente, la escena y sus accidentes en nada cambiarían; pero por su presencia la accidentalidad de la escena adquiere un gran relieve. La voz produce a la vez una dinámica de intensificación inesperada y de modulación extensiva, compleja y hasta contradictoria. Por eso mismo, no puede ser elevada al rango de instancia informativa a no ser que uno esté ciego para observar las dinámicas que ritman la experiencia audiovisual y que crean toda su consistencia.

Su rol, pues, no consiste tanto en completar la representación de la narración como en la de incorporarla a

En relación con esos dos tipos de intervención (acentuación y modulación), se habla de "prosodización" de la semiótica. [N. del T.] 
una verdadera "prosodia audiovisual". La voz interviene en el conjunto del proceso en el que se juega el sentido del filme antes de que este último, eventualmente, cuente o represente cualquier cosa.

\section{Lo que importa en una audiovisión}

En general, contra toda aproximación representacional del lenguaje (en el cognitivismo como en la narratología, o en otras aproximaciones, por ejemplo en la inconología o en los cultural studies), creemos haber mostrado que no es el hipódromo de Longchamp el que se experimenta y se vive en la primera secuencia de Pickpocket, no es su representación el objeto de la secuencia. Por el contrario, es más bien un hipódromo orientado en cierto sentido, declinado en un caso singular. Más precisamente, el texto consiste en una doble diferenciación audiovisual: hay, por un lado, una totalidad unitaria, la "escena" del hipódromo con sus actividades, que es presentada como base; y luego, otras dos macrofiguraciones que producen progresivamente: primero, la totalidad es localizada entre umbrales; luego, es desmultiplicada en una serie de límites que hay que sobrepasar.
Finalmente, el proceso semiótico del filme, del que nuestra aproximación prosódica y retórica ha tratado de dar cuenta, consiste en una heterogeneización progresiva de las figuras y de sus valores. En particular, hemos visto que la configuración previa del hipódromo solo existe en el fondo sonoro, que incluye una totalidad virtual de figuras; y que solamente un número muy restringido de ellas es actualizado por la visión y la acción: los arcos, las ventanillas de apuestas, los torniquetes de entrada y de salida, y también la dama, el bolso... Se trata siempre de figuras-umbrales para la acción accidental del robo. Un número indefinido, virtual, de otras figuras del hipódromo aparecen mezcladas en el fondo, actualizables pero no actualizadas: los rostros de otras gentes, de las que se escuchan, aquí y allá, los pasos y el ajetreo; la carrera de caballos... En los términos de Zilberberg, podríamos decir que el hipódromo es figurado como una mezcla, ya que su existencia tiene el valor de una universalidad inclusiva sin restos ni distinciones; mientras que la acción del robo pasa por esa mezcla para salir de ella, perfilándose como una selección, puesto que su existencia vale como exclusividad absoluta, como un límite. ${ }^{16}$

16 Sobre la semiótica "de la mezcla [mélange] y de la selección [tri]" y sobre los valores "de universo y de absoluto", cf. especialmente Fontanille y Zilberberg 1998: 39-58, donde se desarrolla una rica casuística de las retóricas que producen y conducen esos dos órdenes de valores, eventualmente en competición; y que podrían muy bien adaptarse a lo que pasa en nuestra secuencia. 
En el corazón de la secuencia, la alternancia binaria entre planos de absorción y planos de ruptura lleva al extremo esa dinámica de la selección y de la mezcla. Hemos mostrado ya que en ese momento se trata de absorber toda la escena en un plano totalmente átono, mantener allí lo más posible la configuración "colectiva" del hipódromo y vaciarla de toda consistencia; y luego desplazar el acento al plano de detalle que sigue, con una configuración "individualizante", singularizante. El plano colectivo del hipódromo, con la dama y su acompañante mal encuadrados, dura y se repite, a pesar de su carencia de transformación interna. Es decir, que su existencia (la del plano) es inconsistente, anodina. El plano singular siguiente, con la mano que "penetra" en el bolso y llega hasta el dinero, se encarga de recuperar toda la tensión suprimida al plano precedente, y la concentra en sí. Es como en una pieza musical en la que a un decrescendo sucede un crescendo, a un lento sucede un presto: prosodia del texto fílmico, retórica audiovisual.

(Traducción: Desiderio Blanco)

\section{Bibliografía}

Barthes R. (7 de junio de 1974). "Ĺaventure sémiologique". Le Monde; recogido en (1985) L'Aventure sémiologique. París: Seuil; ahora en (1972-1976). CEuvres complètes IV. París: Seuil, pp. 521-526. [En espa- ñol: (1990). La aventura semiológica. Barcelona: Paidós.]

Bordwell, D. (1985). Narration in the Fiction Film. Madison: University of Wisconsin Press. [En español: (1996). La narración en el filme de ficción. Barcelona: Paidós].

Deleuze, G. (1983). L'image-mouvement. Cinéma I. París: Minuit. [En español: (1983). La imagen-movimiento. Cine I. Barcelona: Paidós.]

Didi-Huberman, G. (1990). Devant l'image. Question posée aux fins d'une histoire de l'art. París: Minuit.

Eco, U. (1979) (1985). Lector in fabula. París: Grasset. [En español: (1981). Lector en fábula. Barcelona: Lumen.]

Fontanille, J. (1999) (2003). Sémiotique $d u$ discours. Limoges: PULIM. [En español: (2001). Semiótica del discurso. Lima: Fondo de Cultura Económica/Universidad de Lima, Fondo Editorial.]

Fontanille, J. y Cl. Zilberberg (1998). Tension et signification. Lieja: Mardaga. [En español: (2004). Tensión y significación. Lima: Universidad de Lima, Fondo Editorial.]

Genette, G. (1972). Figures III. París: Seuil. [En español: (1989). Figuras III. Barcelona: Lumen.]

Geninasca, J. (1977). La parole littéraire. París: P.U.F.

HJelmslev, L. (1985). "The syllabe as structural unit". Nouveaux essais. París: P.U.F.

-. (1935, 1937) (1972). La catégorie des cas. Münich: Fink. [En espa- 
ñol: (1976). La categoría de los casos. Madrid: Gredos.]

—.(1943, 1968) (1971). Prolégoniènes à une théorie du langage. París: Minuit. [En español: (1976). Prolegómenos a una teoría del lenguaje. Madrid: Gredos.]

Lotman, Y. y B. UsPenskij (1975). Tipologia della cultura. Milano: Bompiani.

Metz, Ch. (1971). Langage et cinéma. París: Larousse. [En español: (1973). Lenguaje y cine. Barcelona: Planeta.]

Mitry, J. (1963, 1965) (2001). Esthétique et psychologie du cinéma. París: Cerf. [En español: (1978). Estética y psicología del cine. Madrid: Siglo XXI.]

ZilberberG, Cl. (2006). "Le doublé conditionnement - tensif et rhétorique des structures élémentaires de la signification", en Alonso, J. (éd.) La transversalité du sens. Parcours sémiotiques. Saint-Denis: P.U.V.

-. (2004). "Éloge de la concession". $<$ http://claudezilberberg.net/download/downset.htm>.

- (2002). "Précis de grammaire tensive". Tangence 70: 111-143. Texto integrado a lo largo de (2006). Éléments de grammaire tensive. Limoges: PULIM. [En español: (2006). Semiótica tensiva. Lima: Universidad de Lima, Fondo Editorial].

- (1995). "Plaidoyer pour le tempo", en Fontanille, J. (éd.). Le devenir. Limoges: PULIM.

-. (1993) (2002), "Seuils, limites, valeurs", en HÉnAult, A. (éd.). Questions de semiotique. París: P.U.F. 